\title{
Production and properties of spray dried Clinacanthus nutans using modified corn starch as drying agent
}

\author{
*Ezzat, M.A., Abetra, K., Noranizan, M.A. and Yusof, N.L. \\ Department of Food Technology, Faculty of Food Science and Technology, Universiti Putra Malaysia, \\ 43400 UPM Serdang, Selangor Darul Ehsan, Malaysia
}

\begin{abstract}
Article history:
Received: 30 April 2020

Received in revised form: 5 June 2020

Accepted: 8 June 2020

Available Online: 21 June 2020

Keywords:

Clinacanthus nutans,

Spray drying,

Modified corn starch,

Powder properties,

Storage ability
\end{abstract}

\section{DOI:}

https://doi.org/10.26656/fr.2017.4(5).201

\begin{abstract}
Clinacanthus nutans leaves is a medicinal plant with promising therapeutic effect. The objective of this study was to produce $C$. nutans powder using a spray dryer and to evaluate its physicochemical properties, followed by physical observation after 3 months of storage at room temperature $\left(21 \pm 1^{\circ} \mathrm{C}\right) . \mathrm{C}$. nutans juice with and without the addition of $5 \%(\mathrm{w} / \mathrm{v})$ of modified corn starch (MCS) was spray dried at a feed flow rate of $23 \mathrm{rpm}$, inlet air temperature of $160^{\circ} \mathrm{C}$ and outlet air temperature of $100^{\circ} \mathrm{C}$. Results showed that significantly lower $(\mathrm{p}<0.05)$ values of water activity, moisture content, flowability, particle size, solubility, wettability and dispersibility times, while significantly higher $(p<0.05)$ values of hygroscopicity, bulk and tapped densities were recorded as compared to the spray dried powder without the addition of MCS. These indicated that MCS as drying agent has significantly improved the powder properties and the physical appearance during storage. Furthermore, produced $C$. nutans powder had a significantly higher $(\mathrm{p}<0.05) \mathrm{IC}_{50}$ values, percentage of inhibition and total phenolics content. Also, a strong correlation was observed between total phenolic and antioxidant activity, indicated that encapsulation using MCS successfully protected the thermally sensitive compounds which contributed to high antioxidant activity.
\end{abstract}

\section{Introduction}

Tremendous advances have been made in the discovery of many synthetic drugs in recent years, however, the demand for medicinal plants is still high among a vast majority of the world population (Anand et al., 2019), due to the increase in health awareness among consumers associated with vegetable consumption (Nor Hasni et al., 2020). The World Health Organization (WHO) estimates that around $80 \%$ of the world population in developing countries use plant-based products for primary health care (Yahaya et al., 2015). Besides, the increasing cost of modern medicines paved the way for rural practitioners to rely upon medicinal plants based on their traditional information.

Clinacanthus nutans or known as 'Daun Belalai Gajah' in Malaysia (Figure 1) has diverse and potential medicinal uses in traditional herbal medicine for treating skin rashes, insects and snake bites, lesions caused by herpes simplex virus, diabetes and gout (Aslam et al., 2015). According to Shim et al. (2013), varied contents of bioactive compounds have been documented in $C$. nutans, including protocatechuic acid, chlorogenic acid, ferulic acid, caffeic acid, gendarucin A, gendarucin A isomer, 3,3'-Di-O-methylellagic acid, schaftoside, arabinosyl-glucosyl apigenin isomer, ascorbic acid and two isomeric oxoprolinates (Zulkipli et al., 2017).

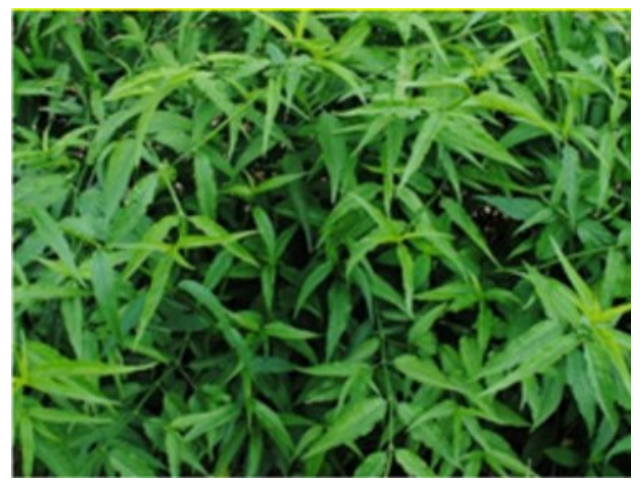

Figure 1. C. nutans leaves

However, C. nutans is highly perishable which results in a microbial deterioration within a few days after post-harvesting. Worse yet, boiling water during juice preparation degraded the heat-sensitive bioactive compounds. To overcome this problem, spray drying is a suitable approach to encapsulate and stabilize the $C$. nutans juice. Besides extending shelf life through high 
moisture removal rate, this method also reduces the cost of packaging, storage and transportation. However, stickiness is one of the issues in spray drying due to the build-up of powder deposit at the outlet of the spray drying chamber which resulting in possible blockage, downtime and loss of product. Another problem which may arise is the spray drying being unfavourable to heatsensitive compounds due to high thermal treatment. Thus, the drying agent is commonly employed during the spray drying process to facilitate powder production.

During the spray drying process, drying agent or also known as wall material, coating the bioactive compounds with the technique called encapsulation. The goals of encapsulation are to entrap and protect the bioactive compounds from nutrient loss or oxidation reactions and to hide sensory characteristics that are not appreciated by consumers. Other than that, the drying agent can increase the glass transition temperature of the product, thereby reduce stickiness and wall deposition during the spraydrying process, producing small solid particles (1-500 $\mu \mathrm{m}$ in size) (Amaral et al., 2019).

Starch is a polysaccharide carbohydrate consisting of a large number of glucose units joined together by glycosidic bonds, comprising of amylose and amylopectin as its macromolecules (Noranizan, 2002). Modified starches have been developed for a very long time and its applications in the food industry are really significant nowadays. Currently, there are no studies reported on the spray dried $C$. nutans using MCS as a drying agent. Hence, the aim of this study is to determine the effect of MCS on properties of spray dried C. nutans, followed by the physical observation of powder after 3 months of storage at room temperature.

\section{Materials and methods}

\subsection{Sample preparation of Clinacanthus nutans juice}

C. nutans Lindau or Sabah Snake Grass leaves were freshly harvested from a commercial farm. Only the top stems were removed from the mother plants. The leaves were hand-plucked from the stems and washed twice under running tap water and tossed. The juice was extracted using a juicer (Phillips, Malaysia) with a fixed ratio, 1:3 of water to leaf. The obtained juice was filtered and utilized right away for spray drying. MCS (Brown and Polson, Malaysia) was purchased from a local supplier.

\subsection{Preparation of Clinacanthus nutans powder by spray drying}

The drying was performed using a spray dryer (Büchi Mini Spray Dryer B-290, Switzerland), a typical laboratory-size model spray dryer at inlet/outlet air temperatures $\left(160^{\circ} \mathrm{C} / 100^{\circ} \mathrm{C}\right)$ respectively, as according to Koç and Dirim (2018). The control of outlet air temperature was regulated by adjusting the feed flow rate at $23 \mathrm{rpm}$. The obtained powder was stored at ambient temperature $\left(21 \pm 1^{\circ} \mathrm{C}\right)$ in a sealed polythene bag under dry and dark conditions for further analysis of powder properties.

\subsection{Moisture content and water activity of Clinacanthus nutans powder}

The moisture content of the powder was measured using moisture analyser (MX-50, Tokyo, Japan) whereas the water activity was measured using Water Activity Meter (Aqualab, Washington, USA).

\subsection{Bulk density}

The bulk density of $C$. nutans powder was measured using a graduated measuring cylinder. Approximately $100 \mathrm{~g}$ of the sample was passed through a sieve with apertures greater than or equal to $1.0 \mathrm{~mm}$ to break up agglomerates that may have formed during storage. The sample was gently introduced into a dry graduated measuring cylinder of $250 \mathrm{~mL}$, carefully levelling the powder without compacting. The bulk density $(\rho)$ was calculated using the following formula:

$$
\rho=\frac{m}{V}\left(\frac{g}{m L}\right)
$$

Where $m$ is the weight of $C$. nutans powder and $V$ is the unsettled apparent volume (Etti et al., 2016).

\subsection{Tapped density}

The tapped density of $C$. nutans powder was obtained by mechanically tapping the graduated measuring cylinder containing the sample. After observing the initial powder volume or mass, the measuring cylinder was mechanically tapped, and volume or mass readings were taken until little further volume or mass change is observed. The mechanical tapping was achieved by lifting the cylinder and allowing it to drop, under its mass and a specified distance. The tapped density in $(\mathrm{g} / \mathrm{mL})$ was calculated using the same formula $\mathrm{m} / \mathrm{V}_{\mathrm{t}}$, as bulk density (Etti et al., 2016).

\subsection{Flowability and cohesiveness}

The flowability and cohesiveness of $C$. nutans powder were evaluated in terms of Carr index (CI) and Hausner ratio (HR) respectively (Jinapong et al., 2008). Both CI and HR were calculated from the bulk and tapped densities of the powder as shown in equations below.

$$
C I=\frac{\rho \text { tapped }-\boldsymbol{\rho b u l k}}{\boldsymbol{\rho} \text { tapped }} \times 100
$$




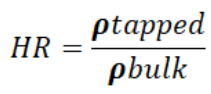

\subsection{Solubility}

The solubility of $C$. nutans powder was determined by adding $5 \mathrm{~g}$ of the sample to $150 \mathrm{~mL}$ of distilled water at room temperature $\left(25 \pm 1^{\circ} \mathrm{C}\right)$ in a $400 \mathrm{~mL}$ beaker. the mixture was immediately stirred using a magnetic stirrer at $1000 \mathrm{rpm}$ to assure systematic stirring, meanwhile the time taken for complete solubility was measured using a stopwatch (Elfalleh et al., 2009).

\subsection{Wettability}

The wettability of $C$. nutans powder was determined by weighing the sample and transferring it into a funnel that is positioned on top of a beaker containing $100 \mathrm{~mL}$ of deionized water. A pestle was placed inside the funnel to block the lower opening. The time is monitored when the pestle was lifted to allow the powder to drop onto the water surface. The time taken until all the powder is visually wetted was recorded (Szulc and Lenart, 2016).

\subsection{Dispersibility}

The dispersibility of $C$. nutans powder was determined by mixing the sample with water at room temperature $\left(21 \pm 1^{\circ} \mathrm{C}\right)$ in a beaker until there were no visible lumps at the bottom of the beaker. The time taken to disperse the powder was measured using a stopwatch (Szulc and Lenart, 2016).

\subsection{Hygroscopicity}

The hygroscopicity of $C$. nutans powder was determined by placing about $1 \mathrm{~g}$ of sample in a desiccator with a saturated solution of sodium chloride $(\mathrm{NaCl})$. After one week, the sample was weighed and the hygroscopicity was expressed as the amount of adsorbed moisture per $100 \mathrm{~g}$ of sample $(\mathrm{g} / 100 \mathrm{~g})$ (Cai and Corke, 2000).

\subsection{Total phenolic content}

The total phenolic content of $C$. nutans powder was determined according to the Folin-Ciocalteu procedure. Different concentrations (50,100, 150, 250 and $500 \mathrm{mg} /$ $\mathrm{mL}$ ) of spray dried $C$. nutans with (5\% MCS) and without drying agent (control) were prepared in ethanol. For each concentration, $2 \mathrm{~mL}$ was added into test tubes contained $1.0 \mathrm{~mL}$ of Folin-Ciocalteu's reagent and 0.8 $\mathrm{mL}$ of sodium carbonate $(7.5 \%)$. The tubes were mixed and allowed to stand for $30 \mathrm{~min}$. Absorption at $765 \mathrm{~nm}$ was measured using spectrophotometer (Thermo Electron Corporation, USA). The total phenolic content was then expressed as gallic acid equivalents (GAE) in milligrams per gram dry material (Kamath et al., 2015).

\subsection{Total antioxidant activity}

The total antioxidant activity of $C$. nutans powder was determined according to 2, 2- Diphenyl-1picrylhydrazyl (DPPH) assay. $0.1 \mathrm{mM}$ of DPPH solution was prepared in methanol. Different concentrations $(4,8$, $12,16$ and $20 \mathrm{mg} / \mathrm{mL})$ of spray dried C. nutans with $(5 \%$ MCS) and without drying agent (control) were prepared in ethanol. For each concentration, $1 \mathrm{~mL}$ of sample was added into $1 \mathrm{~mL}$ of DPPH solution. Control was prepared with an equal volume of methanol and DPPH without adding the sample. The mixture in the test tubes was shaken vigorously and left to stand in the dark for incubation for $30 \mathrm{mins}$ at room temperature. Then, absorbance was measured at $517 \mathrm{~nm}$ using a spectrophotometer (Thermo Electron Corporation, USA) against methanol as blank. Ascorbic acid at various concentrations was used as the standard reference (Basumatary et al., 2015). The percentage of DPPH inhibition was calculated using the following equation:

$$
\% \text { of inhibition }=\frac{A c-A s}{A c} \times 100
$$

where $A c$ is the absorbance value of the control and $A s$ is the absorbance value of the added test samples solution.

\subsection{Particle size of the powder}

The Malvern Panalytical Mastersizer 2000 (Worcestershire, UK) laser diffraction testing instrument was used to evaluate the particle size of the powder. Sample powder was passed through a laser beam resulting in the laser light scattered at a wide range of angles. The detectors measured the intensity of light scattered at that position. A mathematical model (Mie or Fraunhoffer Theory) was applied to generate the particle size of the powder. The final result was reported on an equivalent spherical diameter volume basis.

\subsection{Visual observation of powder's physical appearance}

The powder obtained was sealed in a polyethylene bag and stored in the dark and dry condition at room temperature $\left(21 \pm 1^{\circ} \mathrm{C}\right)$ for 3 months. The powder was kept for a storage period of 3 months as any prolonged storage would result in undesirable effects in the quality of the powder. The powder was then visually observed for any formation of clumps or caking of the powder before and after storage.

\subsection{Statistical analysis}

All statistical analyses were conducted by one-way analysis of variance (ANOVA). Tukey's multiple range tests were employed with a probability of $p<0.05$. The 
linear Pearson correlation was also used to evaluate correlations between total phenolics and antioxidant activity. The software for statistical analysis was Minitab V.16 (Minitab Inc., State College, Pennsylvania, USA).

\section{Results and discussion}

The initial total soluble solid content of the C. nutans juice was found to be $7.0^{\circ}$ Brix prior to the addition of $5 \%$ MCS as a drying agent. Initially, about $2.5 \%$ and $5 \%$ of MCS were used in the juice respectively prior to spray drying in order to determine the percentage of MCS that is able to produce high yield and good quality of the powder. It was found that when $2.5 \%$ of MCS used, the C. nutans powder produced was quite sticky and clumps were also observed in the powder. Thus, the concentration of MCS was increased to $5 \%$ which resulted in powder with good flowability. The total soluble solid content of the juice increased to $10.0^{\circ} \mathrm{Brix}$ after the addition of $5 \% \mathrm{MCS}$.

\subsection{Moisture content and water activity of powder}

The moisture content of the powder should be $<10 \%$ and water activity in the range of 0.1-0.4 depending on the product type. Water activity is defined as the vapor pressure of water in a sample divided by the vapor pressure of pure water at the sample temperature (Nielsen et al., 2012). Water activity measures the availability of free water in a food system that is responsible for biochemical reactions during storage. Therefore, this property provides valuable information about microbial spoilage, chemical stability, and physical stability of the $C$. nutans powder. Moisture content is another important powder property, which is related to the drying efficiency. In addition, moisture content provides information about the texture of the powder since increasing levels of moisture provide water mobility. Water activity and moisture content together provide a complete moisture analysis.

Based on the result obtained in Table 1, the water activity and moisture content of spray dried C. nutans (control) were found to be $0.47 \%$ and $7.31 \%$ respectively. The addition of MCS resulted in a significant decrease $(p<0.05)$ in the water activity and moisture content of $C$. nutans powder, which were $0.34 \%$ and $4.18 \%$, respectively. The addition of MCS has increased the total solid content in the feed as shown by an increase from $7.0^{\circ}$ Brix to $10.0^{\circ}$ Brix and thus, reducing the moisture content of the powder. Apart from an increase in inlet air temperature, $160^{\circ} \mathrm{C}$ and decrease in outlet air temperature, $100^{\circ} \mathrm{C}$, the addition of high molecular weight additives such as MCS to the extract before atomizing is widely used as an alternative way to increase glass transition temperature, $\mathrm{Tg}$ of powder
(Truong et al., 2005). Food products generally formed in a method of rapid heat exchange environment and are not at thermodynamic equilibrium. Depending on their water activity level and molecular weight, they will undergo the shift from a glassy crystallizing temperature to rubbery state matter (Lee et al., 2018). In this research, the nature of high molecular weight of the carbohydrate additive helped to increase the glass transition temperature of the spray drying process. Increasing the glass transition temperature contribute to powder stability, reduce caking and stickiness problem. These results showed that MCS was a useful drying aid in the spray drying process of $C$. nutans extract and as a result it has improved the yield of powder.

Table 1. The properties of spray dried C. nutans powder with and without the addition of MCS

\begin{tabular}{lcc}
\hline \multicolumn{1}{c}{ Powder properties } & $\begin{array}{c}0 \% \mathrm{MCS} \\
(\text { Control})\end{array}$ & $5 \% \mathrm{MCS}$ \\
\hline Water activity $\left(\mathrm{a}_{\mathrm{w}}\right)$ & $0.47 \pm 0.04^{\mathrm{a}}$ & $0.34 \pm 0.01^{\mathrm{b}}$ \\
Moisture content $(\%)$ & $7.31 \pm 0.58^{\mathrm{a}}$ & $4.18 \pm 0.07^{\mathrm{b}}$ \\
Bulk density $\left(\mathrm{kg} / \mathrm{m}^{3}\right)$ & $500.07 \pm 0.21^{\mathrm{b}}$ & $595.82 \pm 0.55^{\mathrm{a}}$ \\
Tapped density $\left(\mathrm{kg} / \mathrm{m}^{3}\right)$ & $556.18 \pm 0.63^{\mathrm{b}}$ & $618.19 \pm 0.22^{\mathrm{a}}$ \\
Flowability $(\mathrm{CI})$ & $14.61 \pm 0.03^{\mathrm{a}}$ & $11.92 \pm 0.12^{\mathrm{b}}$ \\
Cohesiveness $(\mathrm{HR})$ & $1.26 \pm 0.04^{\mathrm{a}}$ & $1.11 \pm 0.04^{\mathrm{a}}$ \\
Solubility $(\mathrm{s})$ & $20.33 \pm 1.53^{\mathrm{a}}$ & $15.33 \pm 0.58^{\mathrm{b}}$ \\
Wettability $(\mathrm{s})$ & $147.00 \pm 0.58^{\mathrm{a}}$ & $106.00 \pm 2.65^{\mathrm{b}}$ \\
Dispersibility $(\mathrm{s})$ & $34.33 \pm 0.58^{\mathrm{a}}$ & $31.67 \pm 0.58^{\mathrm{b}}$ \\
Hygroscopicity $(\mathrm{g} / 100 \mathrm{~g})$ & $15.39 \pm 0.03^{\mathrm{b}}$ & $19.84 \pm 0.30^{\mathrm{a}}$ \\
Particle size $(\mu \mathrm{m})$ & $613.376^{\mathrm{a}}$ & $383.664^{\mathrm{b}}$ \\
\hline
\end{tabular}

MCS: Modified corn starch. Results are expressed as mean \pm standard deviation $(n=3)$. Values with the same superscript in each column are not significantly different $(\mathrm{p}>0.05)$.

\subsection{Bulk density and tapped density of powder}

The physical characteristics of powders are not independent, including those of food powders. For example, a change in the distribution of particle size can result in a simultaneous change in bulk density, flowability, and appearance (Micha, 2009). Bulk density includes the volumes of the solid and liquid materials, all pores and is generally used to characterize a final product obtained by drying (Kurozawa et al., 2009). The bulk density of powders is determined by particle density, which in turn is determined by solid density and particle internal porosity, and also by spatial arrangement of the particles in the container.

The bulk density and tapped density of spray dried C. nutans (control) were found to be $500.07 \mathrm{~kg} / \mathrm{m}^{3}$ and $556.18 \mathrm{~kg} / \mathrm{m}^{3}$ respectively. The increase in the drying air temperature usually causes a decrease in the apparent density since there is a greater tendency to hollow 
particle formation (Walton, 2000). In this research, the inlet drying air temperature was $160^{\circ} \mathrm{C}$, and the outlet drying air temperature was $100^{\circ} \mathrm{C}$. Besides, the moisture content of the control $C$. nutans powder is higher than that of $C$. nutans powder with MCS. The high moisture content of powder causes their gathering into larger aggregations, which causes more empty voids between particles, resulting in a reduction of bulk density (Janiszewska et al., 2008).

However, with addition of MCS as drying agent, there was a significant increase in the bulk density and tapped density of the $C$. nutans powder $(\mathrm{p}<0.05)$, which were $595.82 \mathrm{~kg} / \mathrm{m}^{3}$ and $618.19 \mathrm{~kg} / \mathrm{m}^{3}$ respectively. The higher the initial concentration of the feed solution, the greater the values of apparent density of powders (Janiszewska and Witrowa-Rajchert, 2007). Thus, apart from the low moisture content of the $C$. nutans powder with MCS, the high concentration of the feed solution prior to spray drying also contributed to the increased densities of the powder. A higher bulk density is associated with better powder flow (Niazi, 2013). Tapped density is another important factor related to packaging, transport, and commercialization of powder thus, this value can be useful in terms of weight and amount of material that will fit into a container (Finney et al., 2002). A high-density dry product can be stored in smaller containers in comparison with a low-density product. The heavier material accommodates itself more easily in the spaces among the particles, resulting in higher density (Tonon et al., 2010).

\subsection{Flowability and cohesiveness of powder}

Flow characteristic of powder is judged by the free flowing, semi-free flowing, and cohesive flow. Cohesive flow is considered as the more severe resistance to flow. Both flowability and cohesiveness are significant quality attributes for the manufacturers and end users for packaging, measuring, handling, transportation, bag filling, emptying storage, dosing and mixing (Koç and Dirim, 2017). The flowability and cohesiveness properties of the $C$. nutans powder were evaluated in terms of CI and HR.

Based on the results obtained, both flowability and cohesiveness of spray dried C. nutans (control) were 14.61 and 1.26 respectively. On the contrary, the addition of $5 \%$ MCS as drying agent to the $C$. nutans powder resulted in the flowability and cohesiveness of 11.92 and 1.11, respectively. Thus, the addition of MCS has significantly decreased the value of the two properties $(p<0.05)$. Both flowability and cohesiveness of sample powder were lower than that of control powder, probably due to the lower moisture content of the sample powder in which MCS was added as drying agent. Factors which influence the flow behavior of powder include, particle size, particle distribution, morphology, hygroscopic nature, drying aid and moisture content of material (Seth et al., 2017).

According to Jinapong et al. (2008), the classification of the powder flowability and cohesiveness based on the CI and HR are very good $(<15)$, good $(15-$ $20)$, fair (20-35), bad (35-45) and very bad ( $>45)$, and low $(<1.2)$, intermediate $(1.2-1.4)$ and high $(>1.4)$, respectively. The lower the flowability and cohesiveness, the powder will be less cohesive and more able to flow freely. Food powders obtained by spray drying might have some problems with their properties, such as solubility, flowability and cohesiveness, due to the presence of low molecular weight chemicals which have a low glass transition temperature (Jittanit et al., 2010). They can therefore stick on the dryer chamber wall during spray drying, resulting in low product yield and operational issues. These issues can be fixed before being atomized by adding certain drying agents with high molecular weight such as carbohydrate additives, to the feed.

\subsection{Solubility time of powder}

Food powders constitute a wide range of different powder components in their chemical and physical composition. Solubility, a main determinant of powder quality, is a significant variable in assessing wettability and dispersibility of powder in aqueous solution. The raw materials and additives used, as well as the characteristics of the powder (humidity content and particle size), affect the solubility index of spray dried powder.

The solubility time of spray dried C. nutans (control) was $20.33 \mathrm{~s}$. However, there was a significant decrease $(\mathrm{p}<0.05)$ in the solubility time of the $C$. nutans powder with MCS, $15.33 \mathrm{~s}$. This may be due to the type of carrier agent added as there is variance in powder solubility. Starch is generally difficult to solubilize in water, however modified starch and maltodextrin are more soluble in water. This explains the short time required to solubilize MCS in water, $11.33 \mathrm{~s}$. Literature reviews have stated that the functionality of carbohydrates contribute to the increase of solubility of powder with increase of drying agent used. During rapid heat exchange environment in the drying process, crust formation occurs where the least soluble substance starts to precipitate and form crust at the droplet surface (Lee et al., 2018). The formed crust is mainly constituted of MCS that is highly soluble in nature. This explains why the solubility time of $C$. nutans powder with MCS as drying agent is shorter than that of the control powder. 


\subsection{Wettability time of powder}

Wettability is the ability of powder to overcome the surface tension between themselves and water or the time required to make the powder wet completely. In order to attain high wettability values, high porosity or large pores for bigger particles are desirable (Koç and Dirim, 2017). Besides the effects of physical properties, the chemical composition of the powder also influences wettability depending on the content of fats, proteins, and carbohydrates on their surfaces.

According to the result obtained, the wettability time of spray dried C. nutans (control) was $147 \mathrm{~s}$. However, there was a significant decrease $(p<0.05)$ in the wettability time of the $C$. nutans powder with MCS, 106 s. In the present study, the wettability time was found to have a direct relationship with the solubility time. This is due to the increase in the dissolution of powder components that required less time to wet their surface. Moreover, MCS as drying agent prevented the particle agglomeration of spray dried powder, thus shortened the wettability time. Also, fast dissolution is appeared to be associated with the lower moisture content, which are in line with the study by Goula and Adamopoulos (2004) in the spray drying of tomato pulp. It is explained that powder with low moisture content was less sticky and can be associated with rapid rehydration (Goula and Adamopoulos, 2008).

\subsection{Dispersibility time of powder}

The term dispersibility refers to the dispersion of agglomerates with little stirring. It describes the ease with which the powder may be distributed as single particles over the surface and its ability to be wetted without formation of dry lumps in the reconstituting water. Clump formation reduces dispersibility and can be enhanced if the sink ability is high (Kothakota et al., 2014). Based on the result obtained, the dispersibility time of $C$. nutans powder with $5 \%$ MCS was $31.67 \mathrm{~s}$, significantly shorter $(\mathrm{p}<0.05)$ than that of control $C$. nutans powder which was $34.33 \mathrm{~s}$. Additives have been reported to reduce the interfacial tension between particles and the dispersion media, resulting in enhanced level of dispersibility and shorter dispersibility time in sample powder. Besides, the absence of additives in the control feed produces spray dried powder with reduced particle size. When the size of the particles is small, the adhesive forces between them becomes larger, resulting in poorer flow properties and lower dispersibility in water (Sakurai et al., 2017). Variations in spray drying process parameters and additives type, concentration and dispersant has shown potential improvements in functional and reconstitution properties such as solubility, wettability and dispersibility during food formulations (Yousefi et al., 2011).

\subsection{Hygroscopicity of powder}

Water adsorption measured as hygroscopicity is a critical physical property in powder products as the presence of water influences the deterioration of vitamins, phenolic compounds and other powder properties such as flowability. Hygroscopicity of $C$. nutans powder with $5 \%$ MCS was $19.84 \mathrm{~g} / 100 \mathrm{~g}$, significantly higher $(\mathrm{p}<0.05)$ than that of control $C$. nutans powder, $15.39 \mathrm{~g} / 100 \mathrm{~g}$. The significant increase in the hygroscopicity of the sample powder was probably due to its low moisture content. It was found that the low moisture spray-dried powder has the greater capacity to absorb water from the surrounding air and hence is more hygroscopic (Tonon et al., 2010). The lower the powder moisture content, the higher their hygroscopicity, the greater their capacity to adsorb ambient moisture, which is related to the greater water concentration gradient between the product and the moist air (Bringas-Lantigua et al., 2016). During spray drying, the rapid removal of moisture in the sample powder with MCS results in either a fully amorphous product or some microcrystalline areas dispersed in the amorphous mass. The amorphous form is a meta-stable non-equilibrium. Amorphous products also show high degree of hygroscopicity, contributing to the hygroscopicity of powder (Kothakota et al., 2014).

\subsection{Particle size of powder}

The reconstitution and flow properties of the powder depends on the particle size. Different processing parameters and feed characteristics can affect the distribution of particle size. By an increase in the inlet air temperature, particles became larger sized because of the greater swelling of particles (Tonon et al., 2008). The inlet temperature used in this spray drying process was $160^{\circ} \mathrm{C}$, higher than the outlet temperature, $100^{\circ} \mathrm{C}$. As the inlet air temperature increases, the drying rate increases as well. Because of this, larger-sized particles are produced, due to the early formation of a structure, and would prevent them from shrinking during the drying process (Tonon et al., 2008).

Based on the results, the particle size of control powder was $613.376 \mu \mathrm{m}$, whereas that of the sample powder was $383.664 \mu \mathrm{m}$. The size of particle formed during spray drying is strongly related to feed viscosity, as higher liquid viscosity, the larger the droplets formed during atomization produces larger particles obtained during spray drying (Jinapong et al., 2008). The initial concentration of the control feed before spray drying process was $7.0^{\circ} \mathrm{Brix}$, which increased to $10.0^{\circ} \mathrm{Brix}$ following the addition of $5 \%$ MCS as drying agent. In 
this research, although there was an increase in the concentration of the feed, the particle size of the sample powder produced was small compared to that of control powder. This may be due to the high moisture content of the control powder without MCS. The powder with higher moisture content tends to have a higher bulking weight, caused by the presence of water, which is very denser than the dry solid. This hardened skin prevents the moisture from exiting out of the droplet, and therefore, the particle size increases (Kalantari et al., 2018)

\subsection{Physical appearance of powder before and after 3 months of storage at room temperature}

The sample powder, spray dried with MCS was stored in a sealed polyethylene bag under dry and dark conditions at room temperature $\left(21 \pm 1^{\circ} \mathrm{C}\right)$ for 3 months. The sample powder was stored in such a way that consumers would store at home. Based on the result obtained, clump formation can be seen in the powder in Figure 2.

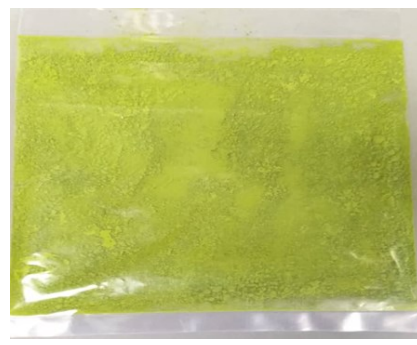

Before storage

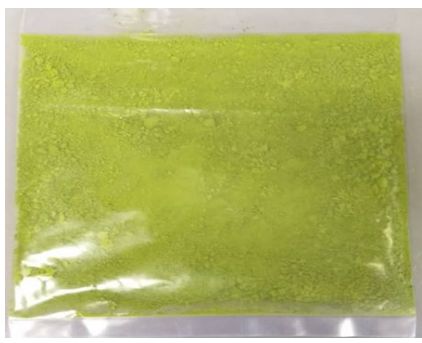

After storage
Figure 2. The physical appearance of spray dried C. nutans with $5 \%$ modified corn starch before and after 3 months of storage at room temperature.

Initially, after exiting the spray dryer, there were no clumps seen and the powder did not appear to be sticky. However, the clump formation observed after the storage period must be due to increasing moisture content of the powder as a result of exposure to the humidity of the environmental conditions during storage (Samborska et al., 2015). The powder particles must have absorbed moisture from the environment. In addition, the moisture absorption by the particles during storage may develop stickiness and cake-like structure which can prevent wetting easily (Koç and Dirim, 2017).

\subsection{Total antioxidant activity}

The ethanolic extract of $C$. nutans leaves was reported to exhibit antioxidant activity and protective effect against free radical-induced hemolysis (Pannangpetch et al., 2007). Based on Table 2, the antioxidant activity of spray dried $C$. nutans were found to be concentration-dependent. The antioxidant activities observed can be attributed to either the different mechanisms exhibited by different polyphenolic compounds that are, tocopherols, flavonoids and other organic acids and to the synergistic effects of different compounds. Studies have shown that many polyphenols make a significant contribution to antioxidant activity and act as extremely efficient free radical scavengers, primarily owing to their redox properties. They play a significant role in adsorbing and neutralizing free radicals, quenching singlet and triplet oxygen or decomposing peroxides (Seth et al., 2017). The phenolics, sulfur-containing glucosides, sulfurcontaining compounds, chlorophyll derivatives, and some phytosterol derivatives that are isolated from $C$. nutans leaves using solvent might be the contributors to the antioxidant activity exhibited (Khoo et al., 2018).

Table 2. Effect of different concentrations of ascorbic acid, spray dried $C$. nutans powder with and without the addition of $\mathrm{MCS}$ on the percentage of inhibition and $\mathrm{IC}_{50}$ values

\begin{tabular}{cccc}
\hline \multirow{2}{*}{\begin{tabular}{c} 
Concentration $(\mathrm{mg} / \mathrm{mL})$ \\
\cline { 2 - 4 }
\end{tabular}} & Ascorbic acid & $\begin{array}{l}\text { 0\% MCS } \\
(\text { Control })\end{array}$ & $5 \% \mathrm{MCS}$ \\
\hline 4 & $15.89 \pm 0.79^{\mathrm{a}}$ & $11.26 \pm 0.56^{\mathrm{b}}$ & $10.6 \pm 0.53^{\mathrm{b}}$ \\
8 & $27.15 \pm 1.36^{\mathrm{a}}$ & $13.91 \pm 0.70^{\mathrm{b}}$ & $14.57 \pm 0.73^{\mathrm{b}}$ \\
12 & $56.95 \pm 2.85^{\mathrm{a}}$ & $20.53 \pm 1.03^{\mathrm{c}}$ & $25.17 \pm 1.26^{\mathrm{b}}$ \\
16 & $66.23 \pm 3.31^{\mathrm{a}}$ & $35.76 \pm 1.79^{\mathrm{c}}$ & $48.34 \pm 2.42^{\mathrm{b}}$ \\
20 & $96.03 \pm 4.80^{\mathrm{a}}$ & $50.99 \pm 2.55^{\mathrm{c}}$ & $64.9 \pm 3.25^{\mathrm{b}}$ \\
\hline \multicolumn{4}{c}{$\mathrm{IC}_{50}$ values $(\mathrm{mg} / \mathrm{mL})$} \\
\hline \multicolumn{4}{c}{$21.28 \pm 1.06^{\mathrm{a}}$} \\
\hline
\end{tabular}

MCS: Modified corn starch. Results are expressed as mean \pm standard deviation $(n=3)$. Values with the same superscript in each column are not significantly different $(\mathrm{p}>0.05)$.

Standard ascorbic acid showed the highest DPPH radical scavenging activity, expressed as the concentration of a sample required to decrease DPPH absorbance by $50 \% \quad\left(\mathrm{IC}_{50}\right.$ value $)$. Moreover, the percentage of inhibition of $C$. nutans spray dried with MCS was found to be significantly $(\mathrm{p}<0.05)$ higher than that of control at the concentrations of $8 \mathrm{mg} / \mathrm{mL}$ and above. Also, the calculated $\mathrm{IC}_{50}$ value was significantly $(\mathrm{p}<0.05)$ lower for $C$. nutans spray dried with MCS as compared to the control sample. It showed better antioxidant potential when compared to control that was spray dried without any drying agent. This result could be explained by the fact that in the sample powder, MCS created a strong impermeable film around the droplets that helps protect the phytochemical compounds from hot drying air. The result showed that the entrapment of the phytochemical compounds in the presence of a drying agent helped prevent some compounds loss during spray drying. Besides, the high spray-drying temperature may associate with the activation of some phenolic compounds, resulting in an increase of antioxidant activity of the powder (Tran and Nguyen, 
2018).

\subsection{Total phenolic content}

C. nutans are commonly rich in phenolic compounds such as flavonoids, phenolic acids, tannins, coumarins, and lignins (Kosai et al., 2016). Quantification was done based on the standard curve of the gallic acid and expressed as gallic acid equivalent (GAE) using the linear equation based. Numerous previous findings have reported the influence of factors such as sample preparation and processing, as well as the extraction procedures on the phenolics yield (Ji et al., 2012).

Based on Table 3, the total phenolic content of $C$. nutans spray dried with $5 \%$ MCS is significantly $(p<0.05)$ higher than that of control at all concentrations which indicates higher phenolic content found in the sample powder. This result may possibly be due to the bound phenolic compounds disengaging from the cellular constituents and forming free phenolic compounds in the powder (Chang et al., 2006). In addition, the extract spray dried with MCS and resulting in low moisture content can cause greater cell disruption and rupture, which may result in more phenolic compounds being released. According to the result obtained, it can be concluded that spray drying performed with the addition of a drying agent has a significant effect on the total phenolic content of the powder. Also, a strong positive correlation with $\mathrm{R}^{2}=$ $0.8527(\mathrm{p}<0.05)$ was detected between total phenolics and antioxidant activity, suggesting that spray drying with MCS was successfully produced $C$. nutans powder with less degradation of the heat-sensitive bioactive compounds and its antioxidant activity.

Table 3. Effect of different concentrations of spray dried $C$. nutans powder with and without the addition of MCS on the total phenolic content

\begin{tabular}{ccc}
\hline \multirow{2}{*}{$\begin{array}{c}\text { Concentration } \\
(\mathrm{mg} / \mathrm{mL})\end{array}$} & \multicolumn{2}{c}{ Total Phenolic Content (mg GAE/g) } \\
\cline { 2 - 3 } & $0 \%$ MCS (Control) & $5 \% \mathrm{MCS}$ \\
\hline 50 & $18.17 \pm 0.91^{\mathrm{b}}$ & $26.5 \pm 1.33^{\mathrm{a}}$ \\
100 & $73.17 \pm 3.66^{\mathrm{b}}$ & $101.5 \pm 5.08^{\mathrm{a}}$ \\
150 & $119.83 \pm 5.99^{\mathrm{b}}$ & $154.83 \pm 7.74^{\mathrm{a}}$ \\
200 & $164.83 \pm 8.24^{\mathrm{b}}$ & $191.5 \pm 9.58^{\mathrm{a}}$ \\
500 & $196.5 \pm 9.83^{\mathrm{b}}$ & $233.17 \pm 11.66^{\mathrm{a}}$ \\
\hline
\end{tabular}

MCS: Modified corn starch. Results are expressed as mean \pm standard deviation $(n=3)$. Values with the same superscript in each column are not significantly different $(\mathrm{p}>0.05)$.

\section{Conclusion}

The results in this study indicated that MCS was a useful drying aid to produce high yield and good quality of $C$. nutans powder. Moreover, the addition of 5\% MCS has significantly improved the powder properties of $C$. nutans in terms of water activity, moisture content, flowability, solubility, wettability, dispersibility times and particle size compared to powder without the addition of MCS. Also, heat-sensitive compounds with high antioxidant activity were well protected through encapsulation using MCS as a drying agent. The physical appearance was still good after 3 months of storage at room temperature, however, there is a tendency for clump formation. Therefore, the application of modified atmosphere packaging (MAP) by removing the oxygen and replacing with the inert gas is recommended in order to control the humidity and maintain the $C$. nutans powder for a longer time.

\section{Conflict of interest}

The authors declare no conflict of interest.

\section{Acknowledgement}

This study was supported by internal funding obtained from Universiti Putra Malaysia.

\section{References}

Amaral, P.H.R.D., Andrade, P.L. and Contro, L.C.D. (2019). Microencapsulation and Its Uses in Food Science and Technology: A Review. In Salaun, F. (Ed.) Microencapsulation - Processes, Technologies and Industrial Applications, IntechOpen E-book. http://doi.org/10.5772/intechopen.81997

Anand, U., Jacobo-Herrera, N., Altemimi, A. and Lakhssassi, N. (2019). A comprehensive review on medicinal plants as antimicrobial therapeutics: Potential avenues of biocompatible drug discovery. Metabolites, 9(11), 1-13. http://doi.org/10.3390/ metabo9110258

Aslam, M.S., Ahmad, M.S. and Mamat, A.S. (2015). A review on phytochemical constituents and pharmacological activities of Clinacanthus nutans. International Journal of Pharmacy and Pharmaceutical Sciences, 7(2), 30-33.

Basumatary, S., Das, A.K., Nanjian, R. and Sharma, G.D. (2015). In vitro Evaluation of Antioxidant properties of Hodgsonia heteroclita (Cucurbitaceae) fruit. Journal of Applied Pharmaceutical Science, 5 (3), 80-83. http://doi.org/10.7324/ JAPS.2015.510.S14

Bringas-Lantigua, M., Pino, J.A. and Aragüez-Fortes, Y. (2016). Influence of process conditions on the physicochemical properties of honey powder produced by spray drying. Revista CENIC Ciencias Químicas, 47, 64-69. 
Cai, Y.Z. and Corke, H. (2000). Production and properties of spray dried Amaranthus betacyanin pigments. Journal of Food Science, 65(7), 12481252. https://doi.org/10.1111/j.13652621.2000.tb10273.x

Chang, C.H., Lin, H.Y., Chang, C.Y. and Liu, Y.C. (2006). Comparisons on the antioxidant properties of fresh, freeze-dried and hot-air-dried tomatoes. Journal of Food Engineering, 77(3), 478-485. https://doi.org/10.1016/j.jfoodeng.2005.06.061

Elfalleh, W., Nasri, N., Marzougui, N., Thabti, I., Yahya, Y., Lachiheb, B. and Guasmi, F. (2009). Physicochemical properties and DPPH-ABTS scavenging activity of some local pomegranate (Punica granatum) ecotypes. International Journal of Food Sciences and Nutrition, 60(Suppl. 2), 925-938. http:// doi.org/10.1080/09637480903067037

Etti, C.J., Yusof, Y.A., Chin, N.L. and Tahir, S.M. (2016). Effects of formulation on flowability of selected herbal powders using compendial methods and powder flow analyser. International Food Research Journal, 23(Suppl.), S225-S230.

Finney, J., Buffo, R. and Reineccius, G.A. (2002). Effects of type of atomization and processing temperatures on the physical properties and stability of spray-dried flavors. Journal of Food Science, 67 (3), 1108-1114. https://doi.org/10.1111/j.13652621.2002.tb09461.x

Goula, A.M. and Adamopoulos, K.G. (2004). Spray drying of tomato pulp: effect of feed concentration. Drying Technology, 22(10), 2309-2330. https:// doi.org/10.1081/DRT-200040007

Goula, A.M. and Adamopoulos, K.G. (2008). Effect of maltodextrin addition during spray drying of tomato pulp in dehumidified air: II. Powder properties. Drying Technology, 26(6), 726-737. https:// doi.org/10.1080/07373930802046377

Janiszewska, E. and Witrowa-Rajchert, D. (2007). Effect of spray drying parameters on rosemary aroma microencapsulation. Polish Journal of Food and Nutrition Sciences, 57(3), 41-43.

Janiszewska, E., Cupial, D. and Witrowa-Rajchert, D. (2008). Impact of spray drying parameters on the quality of protein hydrolysate. Zywnosc Nauka Technologia Jakosc, 5(60), 206-216.

Ji, H.F., Du, A.L., Zhang, L.W., Xu, C.Y., Yang, M.D. and Li, F.F. (2012). Effects of drying methods on antioxidant properties in Robinia pseudoacacia L. flowers. Journal of Medicinal Plants Research, 6 (16), 3233-3239. http://doi.org/10.5897/jmpr12.107

Jinapong, N., Suphantharika, M. and Jamnong, P. (2008). Production of instant soymilk powders by ultrafiltration, spray drying and fluidized bed agglomeration. Journal of Food Engineering, 84(2), 194-205.

j.jfoodeng.2007.04.032

Jittanit, W., Niti-Att, S. and Techanuntachaikul, O. (2010). Study of spray drying of pineapple juice using maltodextrin as an adjunct. Chiang Mai Journal of Science, 37(3), 498-506.

Kalantari, M., Niakousari, M., Haghighi-Manesh, S. and Rasouli, M. (2018). Fig extract drying: The relationship between the main operating parameters of a pilot-scale spray dryer and product specifications. Food Science and Nutrition, 6(2), 325 -333. https://doi.org/10.1002/fsn3.558

Kamath, S.D., Arunkumar, D., Avinash, N.G. and Samshuddin, S. (2015). Determination of total phenolic content and total antioxidant activity in locally consumed food stuffs in Moodbidri, Karnataka, India. Advances in Applied Science Research, 6(6), 99-102.

Khoo, L.W., Audrey Kow, S., Lee, M.T., Tan, C.P., Shaari, K., Tham, C.L. and Abas, F. (2018). A comprehensive review on Phytochemistry and pharmacological activities of Clinacanthus nutans (Burm. F.) Lindau. Evidence-Based Complementary and Alternative Medicine, 2018, 9276260. https:// doi.org/10.1155/2018/9276260

Koç, G.C. and Dirim, S.N. (2017). Spray drying of spinach juice: characterization, chemical composition, and storage. Journal of Food Science, $\quad$ 82(12), 2873-2884. https:// doi.org/10.1111/1750-3841.13970

Koç, G.Ç. and Dirim, S.N. (2018). Spray dried spinach juice: powder properties. Journal of Food Measurement and Characterization, 12, 1654-1668. http://dx.doi.org/10.1007/s11694-018-9781-9

Kothakota, A., Kumar, A., Kumar, M., Juvvi, P., Rao, S. and Kautkar, S. (2014). Characteristics of spray dried dahi powder with maltodextrin as an adjunct. International Journal of Agriculture, Environment and Biotechnology, 7(4), 849-865. http://dx.doi.org/10.5958/2230-732X.2014.01396.5

Kosai, P., Sirisidthi, K. and Jiraungkoorskul, W. (2016). Evaluation of total phenolic compound and cytotoxic activity of Clinacanthus nutans. Indian Journal of Pharmaceutical Sciences, 78(2), 283-286.

Kurozawa, L.E., Morassi, A.G., Vanzo, A.A., Park, K.J. and Hubinger, M.D. (2009). Influence of spray drying conditions on physicochemical properties of chicken meat powder. Drying Technology, 27(11), 1248-1257. https:// doi.org/10.1080/07373930903267187 
Lee, J.K.M., Taip, F.S. and Abdullah, Z. (2018). Effectiveness of additives in spray drying performance: A review. Food Research, 2(6), 486499.

Micha, P. (2009). Physical properties of food powder. Food Engineering, Vol. 1. Retrieved on March 2020 from https://www.eolss.net/sample-chapters/C10/E510-01-05.pdf.

Niazi, M.B.K. (2013). Production of plasticized thermoplastic starch by spray drying. Groningen, The Netherlands: University of Groningen. PhD Thesis.

Nielsen, O.F., Bilde, M. and Frosch, M. (2012). Water activity. Journal of Spectroscopy, 27(5-6), 565-569. https://doi.org/10.1155/2012/414635

Noranizan, M. (2002). Modification of Wheat, Sago and Tapioca Starches by Irradiation and Its Effect on the Physical Properties of Fish Crackers (keropok). Selangor, Malaysia: Universiti Putra Malaysia. PhD Thesis.

Nor Hasni, H., Koh, P.C., Noranizan, M.A., Megat Mohd Tahir, P.N.F., Mohamad, A., Limpot, N., Hamid, N. and Aadil, R.M. (2020). High-pressure processing treatment for ready-to-drink Sabah Snake Grass juice. Journal of Food Processing and Preservation, e14508. [Accepted]. https:// doi.org/10.1111/jfpp.14508

Pannangpetch, P., Laupattarakasem, P., Kukongviriyapan, V., Kukongviriyapan, U., Kongyingyoes, B. and Aromdee, C. (2007). Antioxidant activity and protective effect against oxidative hemolysis of Clinacanthus nutans (Burm. f) Lindau. Songklanakarin Journal Science Technology, 29(Suppl 1), 1-9.

Sakurai, Y., Mise, R., Kimura, S.I., Noguchi, S., Iwao, Y. and Itai, S. (2017). Novel method for improving the water dispersibility and flowability of fine green tea powder using a fluidized bed granulator. Journal of Food Engineering, 206, 118-124. https:// doi.org/10.1016/j.jfoodeng.2017.03.010

Samborska, K., Gajek, P. and Kamińska-Dwórznicka, A. (2015). Spray drying of honey: the effect of drying agents on powder properties. Polish Journal of Food and Nutrition Sciences, 65(2), 109-118. https:// doi.org/10.2478/pjfns-2013-0012

Seth, D., Mishra, H.N. and Deka, S.C. (2017). Functional and reconstitution properties of spray-dried sweetened yogurt powder as influenced by processing conditions. International Journal of Food Properties, 20(7), 1603-1611. https:// doi.org/10.1080/10942912.2016.1214965

Shim, S.Y., Aziana, I. and Khoo, B.Y. (2013).
Perspective and insight on Clinacanthus nutans Lindau in traditional medicine. International Journal of Integrative Biology, 14(1), 7-9.

Szulc, K. and Lenart, A. (2016). Effect of composition on physical properties of food powders. International Agrophysics, 30(2), 237-243. https:// doi.org/10.1515/intag-2015-0084

Tonon, R.V., Brabet, C. and Hubinger, M.D. (2008). Influence of process conditions on the physicochemical properties of açai (Euterpe oleraceae Mart.) powder produced by spray drying. Journal of Food Engineering, 88(3), 411-418. https://doi.org/10.1016/j.jfoodeng.2008.02.029

Tonon, R.V., Brabet, C. and Hubinger, M.D. (2010). Anthocyanin stability and antioxidant activity of spray-dried açai (Euterpe oleracea Mart.) juice produced with different carrier agents. Food Research International, 43(3), 907-914. https:// doi.org/10.1016/j.foodres.2009.12.013

Tran, T.T.A. and Nguyen, H.V.H. (2018). Effects of Spray-Drying Temperatures and Carriers on Physical and Antioxidant Properties of Lemongrass Leaf Extract Powder. Beverages, 4(4), 1-14. https:// doi.org/10.3390/beverages 4040084

Truong, V., Bhandari, B.R. and Howes, T. (2005). Optimization of co-current spray drying process of sugar-rich foods. Part I-Moisture and glass transition temperature profile during drying. Journal of Food Engineering, 71(1), 55-65. https:// doi.org/10.1016/j.jfoodeng.2004.10.017

Walton, D.E. (2000). The morphology of spray-dried particles a qualitative view. Drying Technology, 18 (9), 1943-1986. https:// doi.org/10.1080/07373930008917822

Yahaya, R., Dash, G.K., Abdullah, M.S. and Mathews, A. (2015). Clinacanthus nutans (burm. F.) Lindau: An useful medicinal plant of south-east Asia. International Journal of Pharmacognosy and Phytochemical Research, 7(6), 1244-1250.

Yousefi, S., Emam-Djomeh, Z. and Mousavi, S.M. (2011). Effect of carrier type and spray drying on the physicochemical properties of powdered and reconstituted pomegranate juice (Punica Granatum L.). Journal of Food Science and Technology, 48(6), 677-684. https://doi.org/10.1007/s13197-010-0195-x

Zulkipli, I.N., Rajabalaya, R., Idris, A., Sulaiman, N.A. and David, S.R. (2017). Clinacanthus nutans: a review on ethnomedicinal uses, chemical constituents and pharmacological properties. Pharmaceutical Biology, 55(1), 1093-1113. https:// doi.org/10.1080/13880209.2017.1288749 